\title{
Angioedema and small-cell carcinoma of the lung
}

\author{
THOMAS F ROSS, DIANA LEWIS COLEMAN, JAMES L NAUGHTON \\ From the University of California Department of Medicine, San Francisco, USA
}

Small-cell carcinoma of the lung has a variety of clinical presentations. Symptoms may be due to the primary tumour itself, metastatic disease, systemic effects, or an increasing range of paraneoplastic disorders. ${ }^{1}$ Few reports, however, link this neoplasm with disorders of the skin and mucous membranes. ${ }^{2-4}$ We report here a patient with small-cell carcinoma whose early symptoms and immediate cause of death can be attributed to angioedema.

\section{Case report}

A 47-year-old man who used no medications had episodes of oedema of the face and upper airways in June 1980. Several weeks later he was referred to the University of California, San Francisco, when the episodes became more frequent and an extensive right-lower-lobe infiltrate was found on a chest radiograph.There was no personal or family history of allergies, abdominal pain, oedema of the face or extremities, or respiratory symptoms.

Physical examination showed a cachectic man. Bilateral periorbital oedema was present; but the lips, tongue, and uvula were normal in size and appearance. Pulmonary findings included dullness to percussion, decreased breath sounds, and crackles at the right base without wheeze or stridor. No other abnormalities were detected. Results of laboratory tests were remarkable only for a haematocrit of $29 \%$. The chest film showed an infiltrate in the right lower lobe with loss of volume and pleural effusion. A nodule was also present in the right upper lobe. Gram stain of sputum showed numerous polymorphonuclear leucocytes with mixed bacterial organisms. A sputum culture grew normal oral flora. Bacterial cultures of urine, blood, and cerebrospinal fluid were sterile.

Treatment with intravenous methylprednisolone, cefazolin, and tobramycin was started. On the second hospital day periorbital oedema and stridor developed. Examination of the ears, nose, and throat revealed a normal tongue but swollen, erythematous arytenoids. Cardiac examination and the chest radiograph showed no change. Antibiotics were discontinued and treatment was started with subcutaneous epinephrine $0.5 \mathrm{ml}(1: 1000)$, intravenous diphenhydramine $50 \mathrm{mg}$," and intravenous methylprednisolone $60 \mathrm{mg}$, with moderate clinical improvement. Over subsequent hours several similar epidoses occurred, each with less response to this regimen. Early on the third hospital day the patient died of irreversible respiratory arrest.

Postmortem examination showed small-cell carcinoma originating in the right lung with widespread pulmonary and extrapulmonary metastases. Appreciable oedema of the

Reprints will not be available. face, upper extremities, piriform sinuses, arytenoids, and vocal cords was noted. There was no evidence of thoracic venous or lymphatic obstruction by the tumour.

\section{Discussion}

The patient had showed features typical of angioedema-0 that is, recurrent episodes of oedema of the face, extremities, and upper airways with respiratory obstruction. The poor response to drugs, including epinephrine, antihis $₫ \mathbb{D}$ tamines, and steroids, is also characteristic of this disorder $\mathbb{\Phi}$ Postmortem findings further support the diagnosis. Micro 3 scopic sections of the larynx showed submucosal oedema, venular dilatation, and mast cell degranulation (fig). These histological changes are consistent with those previousl reported in cases of angioedema. ${ }^{5}$

Angioedema can be caused by allergic reactions, chemical histamine releasers, immune complex disease, physicaf stimuli, and several rare disorders. ${ }^{6}$ There is nothing to suggest any of these causes in this patient. The other causes of angioedema include disorders with an abnormality in the complement system, hereditary angioneurotic oedema and $\mathrm{Q}$ acquired angioedema, and a recently described idiopathic $\vec{\sigma}$ form. ${ }^{7}$ Hereditary angioneurotic oedema seems unlikely 3 given the absence of a typical family history and the lack of previous symptoms. The idiopathic form also seems un likely. These patients are usually in their early 30 s and do not have associated disorders; they generally have a more benign course than our patient had. The historical an का clinical findings in this case best support a diagnosis of acquired angioedema. This disorder has been reported in association with several neoplasms, most of which have been lymphoproliferative disorders. ${ }^{6-8}$ Cohen et al reportedo the only case associated with rectal carcinoma. ${ }^{9}$

In hereditary angioneurotic oedema and acquiredo angioedema $\mathrm{C1}$ esterase inhibitor levels $(\mathrm{C} 1 \mathrm{INH})$ are low but $\mathrm{C} 1$ is depressed only in the-latter. Complement levelso are usually normal in the idioputhic form. These observa tions suggest that the cause of hereditary angioneurotic oedema is a genetic deficiency of $\mathrm{C1}$ INH, while the acquired form may reflect activation of $\mathrm{C} 1$ by an immunological product of the tumour, with secondary consumptionw of C1 INH. ${ }^{6}$ Complement studies could not be performed in our patient or his consanguineous relatives.

Hereditary angioneurotic oedema may improve with long-term androgen treatment but there have been nos controlled studies of treatment in acquired angioedema When this has been associated with lymphoproliferative disorders, antitumour treatment has produced remission of the acquired angioedema. The patient with rectal car $\frac{?}{4}$ cinoma did not respond to surgical resection but di\& improve with androgen (danazol) treatment. ${ }^{9}$ 


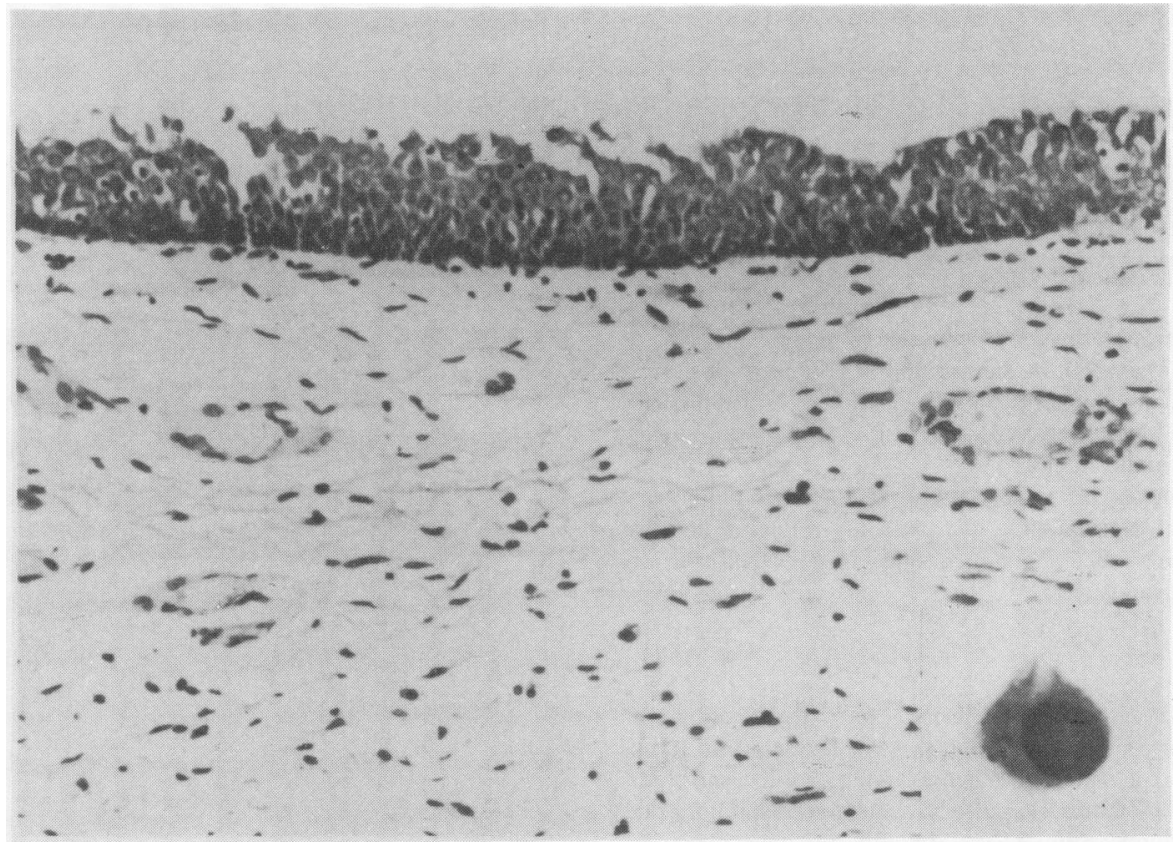

Larynx at postmortem examination: prominent submucosal oedema with separation of collagen fibres and venular dilatation with perivascular accumulation of mononuclear cells. (Toluidine blue, $\times 350$ ). Inset: Partially degranulated mast cell. (Toluidine blue, $\times 2000)$.

In conclusion, on the basis of the clinical and pathological findings in our patient with small-cell carcinoma and angioedema, we believe that this is a case of acquired angioedema, only the second to be reported in association with a non-haematological carcinoma.

\section{References}

${ }^{1}$ Hyde L, Hyde CI. Clinical manifestations of lung cancer. Chest 1974;65:299-306.

${ }^{2}$ Curth HO. Dermatoses and malignant internal tumors. Arch Dermatol 1955;71:95-107.

${ }^{3}$ Knowles JH, Smith LH Jr. Extrapulmonary manifestations of bronchogenic carcinoma. $N$ Engl J Med 1960;262:505-10.

${ }^{4}$ Rassam JW, Anderson G. Incidence of paramalignant disorders in bronchogenic carcinoma. Thorax 1975;30:86-90.
${ }^{5}$ Sheffer AL, Craig JM, Willms-Kretschmer K, Austen KF, Rosen FS. Histopathological and ultrastructure observations on tissues from patients with hereditary angioneurotic edema. J Allergy 1971;47:292-7.

${ }^{6}$ Gelfand JA, Boss GR, Conley CL, Reinhart R, Frank MM. Acquired C1-esterase inhibitor deficiency and angioedema: a review: Medicine 1979;58:321-8.

${ }^{7}$ Freed DL, Buisseret PD, Lloyd MJ, Pumphrey RS, Garretts M. Angioedema responding to antiprotease treatment but without abnormalities of the complement system. Clin Allergy 1980;10:21-3.

${ }^{8}$ Fiechtner JJ, Marx JJ Jr, Wolski KP, Schloesser LL. Acquired angioedema, autoimmune hemolytic anemia, and lymphona: resolution after therapy. Clin Immunol Immunopathol 1980;15:642-5.

${ }^{9}$ Cohen SH, Koethe SM, Kozin F, Rodey G, Arkins JA, Fink JN. Acquired angioedema associated with rectal carcinoma and its response to danazol therapy. $J$ Allergy Clin Immunol 1978;62:217-21. 